OPEN ACCESS

Edited by: Billy Osteen,

University of Canterbury, New Zealand

Reviewed by: Adrian Sin Loy Loh, National Junior College, Singapore Grady Venville,

Australian National University, Australia

Miriam Sullivan,

Edith Cowan University, Australia

${ }^{*}$ Correspondence:

Nantida Sripaoraya nantida@nsm.or.th Nancy Longnecker nancy.longnecker@otago.ac.nz

Specialty section: This article was submitted to

STEM Education,

a section of the journal

Frontiers in Education

Received: 02 June 2021 Accepted: 10 January 2022 Published: 22 February 2022

Citation:

Sripaoraya N, Spronken-Smith $R$ and Longnecker N (2022) Intensive, Short-

Term Presenting With a Science

Outreach Program Enhances Positive Science Attitudes and Interest in

Lifelong Learning About Science.

Front. Educ. 7:719686.

doi: 10.3389/feduc.2022.719686

\section{Intensive, Short-Term Presenting With a Science Outreach Program Enhances Positive Science Attitudes and Interest in Lifelong Learning About Science}

\author{
Nantida Sripaoraya ${ }^{1,2 *}$, Rachel Spronken-Smith ${ }^{3}$ and Nancy Longnecker ${ }^{1 *}$ \\ ${ }^{1}$ Centre for Science Communication, University of Otago, Dunedin, New Zealand, ${ }^{2}$ National Science Museum, Bangkok, \\ Thailand, ${ }^{3}$ Higher Education Development Centre, University of Otago, Dunedin, New Zealand
}

This study investigated impacts of intensive, short-term participation as a science outreach presenter on attitudes towards science and interest in lifelong learning about science. Participants included high school and university students who volunteered to assist as presenters over 1 week when Science Caravan -an extensive science outreach program in Thailand, run by the National Science Museum-visited their locality. This study employed mixed methods over two phases. Phase One involved three questionnaires. Two questionnaires were administered to current presenters $(N=690)$, pre-presenting (before training) and immediately post-presenting at 12 locations of the Science Caravan tour in 2017-2018. A third questionnaire collected data from previous, alumni presenters $(n=726)$. Phase Two involved interviews with current presenters $(n=19)$ and alumni presenters $(n=19)$. While presenters already had positive attitudes towards science, the brief but intensive experience of being a Science Caravan presenter enhanced science attitudes in four scales - with more positive attitudes about Self-concept in science, Value of science to society, and Future participation in science, and decreased Anxiety about science presenting. Participation had a greater impact of reducing anxiety in female presenters compared to male presenters. The experience of presenting with Science Caravan led to the development of more positive attitudes towards science and increased interest in lifelong learning activities regarding science, including presenters' interest in science-related education. The increased interest in lifelong learning activities was correlated with positive attitudes about and self-efficacy in science. This study provides evidence that a short-term, intensive experience of science outreach can lead to increases in positive attitudes towards science and lifelong learning.

Keywords: science outreach, presenter, lifelong learning about science, attitudes towards science, science presenting 


\section{INTRODUCTION}

The utilization of scientific knowledge and technology facilitates life in the workplace, offers healthier and longer lives, and provides more convenient lifestyles (Triyarat, 2017). Understanding scientific knowledge and engaging with science can improve science literacy. Kawamoto et al. (2013) suggested that improving scientific literacy in modern society is relevant for determining scientific policies that support national development. Negative attitudes about studying science are of concern to governments around the world (Venville et al., 2013), and research has endeavored to find ways to increase students' positive attitudes towards science (Kind et al., 2007). It is important to increase interest in lifelong learning in science (Cobern, 2015). The development of effective science education is a notable strategy used to promote scientific literacy (Chalamwong and Pomlakthong, 2004).

Lifelong learning is defined as "all learning activities ... undertaken throughout life, with the aim of improving knowledge, skills, and competence within a personal, civic, social, and/or employment-related perspective" (European Commission, 2001, p. 9). According to Tuijnman and Boström's (2002) review, lifelong learning has several features, which may be different from other education approaches: (1) such learning is based on learners' needs; (2) self-directed learning is central to individual learning throughout life; and (3) such learning can take place in a variety of settings. In this sense, lifelong learning is not confined to structured, institutional settings such as schools, libraries, museums, science centers, and zoos, but can include daily experiences at home, at play, from travel, reading magazines, surfing the internet, watching television, etc. (Longnecker, 2016). Therefore, many efforts towards bridging the gap of an individual's learning between formal and informal contexts reflect an awareness of lifelong learning approaches in society (Rajala et al., 2016). For example, Jones et al.'s (2017) study found that experiences derived from engaging in science-related hobbies, events, and leisure activities, which mostly began in childhood, influenced people's lifelong science learning interest.

From the perspective of learners, encountering science information in a wide range of contexts outside school settings-both structured and unstructured-can influence attitudes and abilities (Lin and Schunn, 2016). In the context of both structured and free-choice learning environments, Longnecker (2016) noted that an individual's engagement with and use of new information is influenced by the individual's identity, a construct that comprises values, beliefs, attitudes, prior understanding, and skills. This model is consistent with findings of Kouthouris and Spontis (2005) who asked 329 university students in the United States about their intention to participate in outdoor activities. Their results indicated that students' intentions to participate in the activities were significantly predicted by perceived behavioral control, role identity, and attitudes toward participation. Engaging in learning environments where learners are self-directed and intrinsically motivated to discover and explore for themselves can improve their perceived value of particular, domain-specific knowledge (Kong et al., 2014). Moreover, participating in sciencebased activities can influence students' attitudes towards science. Gibson and Chase (2002) showed a longitudinal impact of an inquiry-based, hands-on science program, when attitudes towards science became more positive. These findings align with those of studies where there have been positive impacts on students' interest in science and thus an eagerness to learn science by using science-based activities (Laursen et al., 2007).

It is apparent that many factors influence science attitudes, and these attitudes in turn affect science learning. Previous research has found strong links between contributing to science outreach and positive attitudes towards science (Larsen, 1994; Toolin, 2003). This study fills a gap related to short-term science outreach programs, that participation as volunteers might encourage positive attitudes towards science, which could in turn contribute to lifelong science learning behaviors. Analyses of attitudes towards science from such programs will help predict whether and how students will engage with science later in life and in their careers. Furthermore, improving understanding of how factors influence attitudes towards science can enable teachers, counsellors, and outreach organizers to enhance student achievement.

\section{Focus of This Study}

This study focuses on a short-term science outreach program-the Science Caravan, an initiative run by the National Science Museum (NSM), Thailand-and is guided by these research questions:

1) Does presenting in a short-term outreach program change presenters' attitudes towards science? If so, how?

2) Does presenting in a short-term outreach program influence lifelong learning interest and behavior of volunteer outreach presenters?

\section{Theoretical Framework}

This study was informed by the Theory of Planned Behavior and self-efficacy. Both constructs are described below.

\section{The Theory of Planned Behavior}

The Theory of Planned Behavior (Ajzen, 1991) is used for predicting behavior in many various contexts (Ajzen and Driver, 1992). The Theory of Planned Behavior states that an individual's intention can predict the possibility of engaging in action, and that this intention is influenced by attitude towards the behavior, subjective norm, and perceived behavioral control. In other words, individuals have beliefs regarding their ability, knowledge, and skills to perform the behavior, beliefs about what others think, and beliefs about whether they have sufficient resources and opportunity. According to the Theory of Planned Behavior, the more favorable the attitude and subjective norm concerning a behavior, and the higher the perceived behavioral control, the more likely a person will be to perform the behavior (Ajzen, 1985). However, internal and external factors can interfere with performing intended behavior (Ajzen, 1985). For example, to carry out the behavior of visiting a 


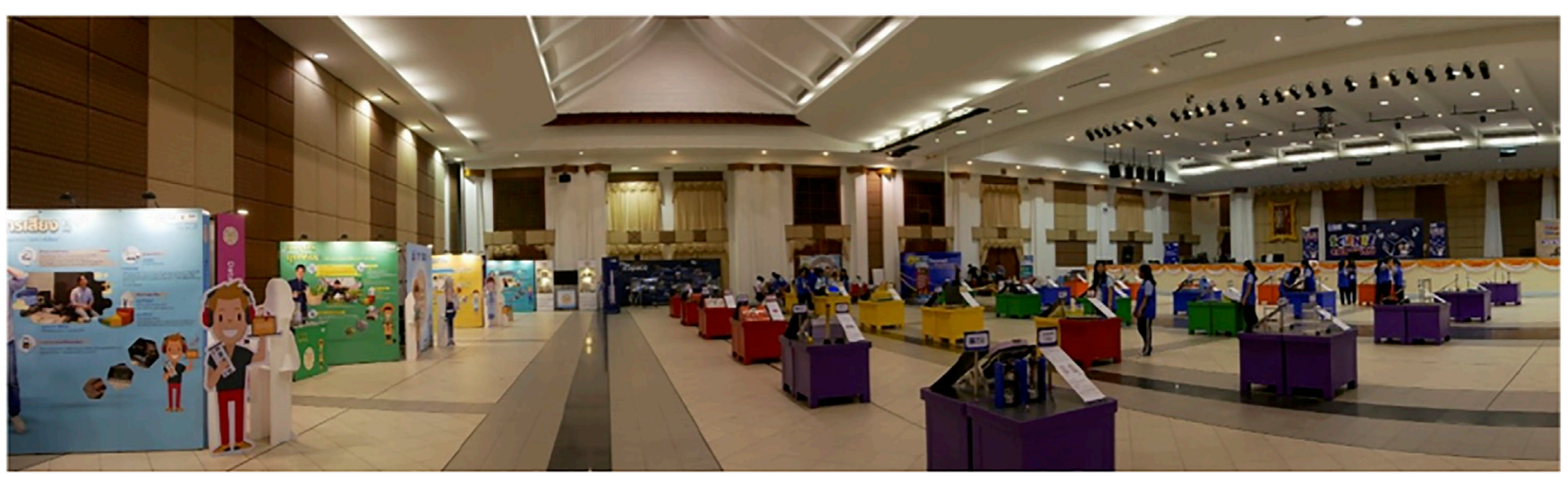

FIGURE 1 | A typical setting of the exhibition space of Science Caravan being prepared for opening to visitors.

science museum on weekends, learners may require not only positive attitudes towards science and self-efficacy in science but also resources (time and money). One important external factor is support (Longnecker, 2016); in the example of visiting a science museum, children in particular would need family support and transport.

\section{Self-Efficacy}

Self-efficacy is described as "people's judgments of their capabilities to organise and execute courses of action required to attain designated types of performances" (Bandura, 1986, p. 94). Bandura (1986) found that individuals with the same level of ability can master the same task at different levels of performance. Individuals with higher self-efficacy are more likely to have higher performance than those with lower self-efficacy (Frey, 2018). In different contexts, an individual can perform at a different level of achievement if that individual perceives a different level of selfefficacy. As such, learners are more likely to carry out a behavior if they have a high level of self-efficacy. Self-efficacy also influences outcome expectations; individuals who judge themselves with higher efficacy will expect more positive performance outcomes (Bandura, 1986). For example, a student who is confident in their ability in science may anticipate positive achievements (Lent et al., 2008).

\section{METHODS}

The case study context is described before detailing the research methods, including the participants, data collection methods, and analyses.

\section{Case Study Context: NSM Science Caravan}

This study focused on Science Caravan, an outreach program of the NSM Thailand. To serve Thai youth across the country, Science Caravan was initiated in 2006 to promote public awareness of science and technology and inspiration about science in Thai students in rural and regional communities. Another aim is to encourage skills development regarding creativity, critical thinking, problem-solving, and science process skills. Science Caravan is a large-scale science outreach program, bringing 60-80 science exhibits (Figure 1), and handson activities, science shows, two science labs, a mobile planetarium, and professional teacher training to communities in at least 20 Thai provinces each year. Over more than 10 years, about 8,000 volunteer presenters have facilitated and encouraged approximately $1,000,000$ visitors to be actively involved in science activities.

The Science Caravan has developed a program for volunteer presenters and works with local communities to offer an opportunity at each venue for 60-70 local high school or undergraduate students who assist Science Caravan as presenters. Since basic science knowledge is a requirement for presenters, most presenters are recruited from undergraduate students studying science majors or high school students studying in the science stream.

A Science Caravan trip starts on a Saturday morning, with transportation to the target location. On Sundays and Mondays, while Science Caravan is being set up, 60-70 local presenters receive 2 days of training from NSM staff in essential science communication, natural science, and critical thinking in relation to solving common problems that arise at Science Caravan. During the science communication training, presenters develop their skills and are explicitly told of their value to the Science Caravan program by inspiring visitors about science. After receiving training, each presenter is assigned to a specific exhibit or activity, which they are responsible for from 8.00 a.m. to 4.30 p.m., Tuesday to Friday; they receive mentorship by NSM staff. After finishing the activities each day, presenters are given feedback about their performance and told about plans for the next day. After 4.30 p.m. on Friday afternoon, there is a debrief for presenters while Science Caravan is disassembled in preparation for moving to the next location.

This paper reports one part of results from a research project examining the impact of intensive contribution as a presenter in a short-term (6-day) program in an informal science learning environment (Sripaoraya, 2020). For this paper, a case study approach with mixed methods was adopted and comprised two phases. Phase One used a convergent parallel design to examine both research questions. Data were gathered using questionnaires 
administered to current and alumni presenters. Phase Two involved in-depth interviews investigating how contributing as a presenter influenced attitudes towards science and lifelong learning behavior. Phase Two used explanatory sequential design (Guest, 2013), in which the quantitative data set in Phase One provided information for further data collection involving follow-up telephone interviews and qualitative analysis. The research design provided triangulation since two sources-current and alumni presenters-provided quantitative and qualitative data, which were collected separately and then merged for analysis. This research was approved by the Human Research Ethics Committee of the University of Otago, New Zealand (Reference 17/116). The following subsections provide summaries of participants, survey instruments, the interviews, and data analyses.

\section{Participants}

There were two groups of participants recruited for this study: current presenters with the Science Caravan and alumni presenters. Current presenters included those at each of the 12 venues of one 2017-2018 Science Caravan tour. Approximately 60 high school students (16+ years old) or undergraduate students who volunteered to be presenters were invited to complete two surveys, and were asked for consent to be interviewed. The pre-presenting survey was administered on the morning of the first day of training, before training began $(n=764)$, and the post-presenting survey after presenters had finished on day six $(n=723)$. A month after the Science Caravan tour had finished at each location, 19 recent presenters were invited for follow-up interviews (10 high school students and nine university students).

The second group of participants included alumni who had been presenters with Science Caravan between 2005 and 2017. This group allowed investigation of the longer-term impact of being presenters. The recruitment of alumni presenters was conducted via the social media platform Facebook คาราวานวิทยาศาตร page (Science Caravan) with 15,052 followers, and Enjoy Science Career page with 510 followers (the numbers of followers recorded on September 13, 2017). Invitations to participate in the survey, with a link to the online survey, were posted and advertised on the Facebook pages and resulted in 938 clicks on the survey link, with 726 (77.4\%) completing the survey. Nineteen alumni presenters who had completed the survey were selected for follow-up interviews to investigate in-depth views of full-time workers and students at either the undergraduate or postgraduate level.

\section{Survey Instruments}

Three questionnaires were developed in English to explore the research questions:

- Pre-presenting survey for current presenters before participation in science communication training;

- Post-presenting survey for current presenters at the end of the final day of NSM Science Caravan; and

- Alumni Survey as a retrospective survey of alumni presenters.
Each survey was divided into four parts, and translated and administered in Thai via Qualtrics ${ }^{\mathrm{XM}}$, a web-based survey platform. Each survey began with demographic questions, followed by questions related to self-efficacy in science knowledge, attitudes towards science, and lifelong learning behaviors. Lifelong learning behaviors consisted of seven items focusing on free-time activities associated with science, with items developed by the researchers, informed by Venville et al. (2013).

We predicted that participation as a presenter would result in changes in four attitude dimensions: (I) Future participation in science, (II) Value of science to society, (III) Self-concept about science, and (IV) Anxiety about science presenting. Twenty-four items were included in the questionnaire; they were adapted from three sources (Weinburgh and Steele, 2000; Kind et al., 2007; Hillman et al., 2016) and developed to suit the particular Thai context. The items consisted of positive and negative statements in order to confirm that respondents were paying attention; items with five-point Likert-type responses were used, ranging from strongly agree to strongly disagree.

Exploratory factor analysis was conducted using SPSS Version 24 to summarize the 24 items into smaller sets of dimensions or scales (Pallant, 2011). In this study, three sets of statements, namely, "attitude towards science" (Table 1), "self-efficacy in science" (Table 2), and "lifelong learning behavior about science" (Table 3), were extracted. The Oblimin rotation for postpresenting surveys is presented here, revealing four factors for "attitude towards science" (Table 1) and one factor for "selfefficacy in science" (Table 2). Varimax rotation identified one factor for "lifelong learning behavior about science" (Table 3).

Cronbach's alpha is widely used to measure reliability and provide a measure of internal consistency of a set of items where all the subset of items in the survey are intended to measure the same concept (Tavakol and Dennick, 2011). Cronbach's alpha for all scales in each survey were acceptable, ranging from 0.73 to 0.89 .

\section{Interviews}

All interviews were conducted between October 2017 and April 2018 by the first author. Each interview took approximately 15-30 min, and was recorded with permission. The interview questions were developed in English, with feedback from science communication researchers at the University of Otago, and then translated into Thai for Thai participants. The main questions probed attitudes towards science and science engagements to answer the research questions associated with participants' experience with the Science Caravan program.

\section{Data Analyses}

Paired $t$-tests were used to compare the differences between prepresenting and post-presenting scores on attitude scales. A twoway, between-groups analysis of variance was used to examine the impact on the scores of attitudes towards science of the intervention of presenting with Science Caravan, gender, and education level. Wilcoxon sign rank test was employed to analyze items for Lifelong learning about science and compare results for pre-presenting and post-presenting. Hierarchical multiple 
TABLE 1 | Summary of rotated factor analysis loading results $>0.35$ for 24 items on attitude towards science in the post-presenting survey.

Attitude item

\section{Self-concept in science \\ Anxiety about science resenting}

I can talk about science with others.

I learn science quickly.

I do very well in science studies.

I usually understand what people are talking about in science.

Science is easy for me.

I have a good feeling toward teaching science to school children.

I would enjoy studying science.

It makes me anxious about how I will deal with questions from students.

I worry about explaining the science content to school children.

It makes me nervous when school teachers ask me to explain science-

related topics.

I feel tense when someone talks to me about science.

I become anxious when it is time to explain a science concept in front of my

classmates.

Discoveries in science do not affect how I live

Science can produce useful technology

Science is useful in helping to solve the problems of everyday life.

Everyone should have some basic scientific knowledge.

It is exciting to learn about new things happening in science.

Science is not important to a country's development.

If I try hard, I can understand science.

People don't need to understand science because it does not affect their lives.

I would like to be a scientist.

I would like to be a science teacher.

I would like to have a job working with science.

I would like to study more science in the future.

Cronbach's alpha

$\begin{array}{cc} & \text { presenti } \\ 0.69 & - \\ 0.69 & - \\ 0.67 & - \\ 0.63 & - \\ 0.59 & - \\ 0.43 & - \\ 0.43 & - \\ - & 0.81 \\ - & 0.72 \\ - & 0.72 \\ - & 0.71 \\ - & 0.66 \\ & 0.37 \\ - & - \\ - & - \\ - & - \\ - & - \\ - & 0.36 \\ - & - \\ - & - \\ - & - \\ - & - \\ - & - \\ - & - \\ - & 0.82 \\ 0.86 & \end{array}$

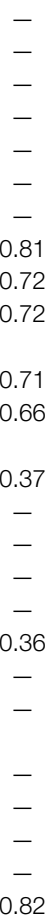

Value of science to society
Future participation

in science

\begin{tabular}{|c|c|}
\hline- & - \\
\hline- & - \\
\hline- & - \\
\hline- & - \\
\hline- & - \\
\hline- & - \\
\hline- & - \\
\hline- & - \\
\hline- & - \\
\hline- & - \\
\hline- & - \\
\hline- & - \\
\hline- & - \\
\hline 0.68 & - \\
\hline 0.61 & - \\
\hline 0.57 & - \\
\hline 0.54 & - \\
\hline 0.47 & - \\
\hline 0.46 & - \\
\hline 0.38 & - \\
\hline- & 0.79 \\
\hline- & 0.68 \\
\hline- & 0.58 \\
\hline- & 0.50 \\
\hline 0.73 & 0.75 \\
\hline
\end{tabular}

TABLE 2 | Summary of rotated factor analysis loading results >0.35 for 3 items on Self-efficacy in science in the post-presenting survey.

\section{Scale}

Self-efficacy in science
Item

I have a lot scientific knowledge

I can get good marks in science class

My understanding of science is good

Cronbach's alpha
Factor loading

TABLE 3 | Summary of rotated factor analysis loading results $>0.35$ for 7 items on Lifelong learning about science in the post-presenting survey.

\section{Scale}

Lifelong learning about science
Item

Factor loading

$\begin{array}{lr}\text { Visiting science museum, science center, zoo } & 0.62 \\ \text { Watching science documentaries or TV show } & 0.77 \\ \text { Reading science articles } & 0.80 \\ \text { Browsing updated science news } & 0.83 \\ \text { Searching for science information that is interesting to you } & 0.83 \\ \text { Visiting website, Facebook, and blogs about science } & 0.81 \\ \text { Participating in science events or public lectures about science or related topics } & 0.76 \\ \text { Cronbach's alpha } & 0.89\end{array}$

regression was used to assess the ability of the combined scales of science attitudes (Future participation in science, Value of science to society, self-concept in science, and Anxiety about science presenting) and the scale for self-efficacy in science knowledge to predict intentions for Lifelong learning about science, after controlling for the influence of gender and education level.

To explore the intervention in relation to longer-term impact, 678 alumni presenters who had contributed in different time frames between 2007 and 2017 were asked to rate their agreement 
TABLE 4 | Current presenters' attitudes towards science before and after presenting on 5-point, Likert-type scaled items, tested with paired sample $t$-test for the mean scores of current presenters $(n=690)$.

\begin{tabular}{|c|c|c|c|c|}
\hline \multirow[t]{2}{*}{ Scales } & \multirow{2}{*}{$\frac{\text { Pre-presenting }}{\text { Mean (S.D.) }}$} & \multirow{2}{*}{$\frac{\text { Post-presenting }}{\text { Mean (S.D.) }}$} & \multirow[t]{2}{*}{$t$} & \multirow[t]{2}{*}{$d$} \\
\hline & & & & \\
\hline Self-concept in science & $3.52(0.46)$ & $3.78(0.51)$ & $15.58^{\star \star \star}$ & 0.55 \\
\hline Future participation in science & $3.43(0.65)$ & $3.62(0.68)$ & $9.25^{\star \star \star}$ & 0.28 \\
\hline Value of science to society & $4.11(052)$ & $4.25(0.52)$ & $8.03^{\star \star \star}$ & 0.27 \\
\hline Anxiety about science presenting & $3.08(0.54)$ & $2.81(0.70)$ & $10.98^{\star \star \star}$ & 0.43 \\
\hline
\end{tabular}

Higher scores indicate more positive attitudes towards science with a maximum score of 5 . The exception is the Anxiety about science presenting scale, where lower scores indicate less anxiety. N.B.: ${ }^{* * *} \mathrm{p}<0.001 . \mathrm{d}=$ Cohen's d effect size: $>0.2$, small; >0.5, medium (Sawilowsky, 2009).

with the 24 attitude items on a five-point Likert-type. There was no difference in responses in any of the four attitude scales of those who presented in different years, indicating that the perception of alumni presenters from each year is similar. Respondents had similar experiences while presenting with the Science Caravan program, irrespective of which year they participated and so further analysis pooled results from all alumni presenters.

A thematic analysis approach as described by O'Leary (2010) was used to analyze 38 transcripts from interviews in order to interpret meaning in speech. Coding schemes were developed based on the research questions, and meaning was extracted from a sentence, paragraph, and message, and then similar meanings were grouped into codes (Kvale and Brinkmann, 2009; Daniel and Harland, 2018). The coding scheme was examined in English by all authors, using three translated transcripts. Experts recommend that the minimum acceptable inter-coder agreement is $80 \%$ (McHugh, 2012). Fleiss' kappa, a measure of inter-coder agreement, was also calculated to determine the level of agreement between two or more coders (Fleiss et al., 2003; Laerd Statistics, 2019). In this study, the value of kappa, $\kappa=0.904$ (95\% CI, 0.898 to 0.910 ), $p<0.001$, showed that there was very consistent agreement between the coders (McHugh, 2012). Once intercoder reliability was determined to be adequate, the first author coded the remaining transcripts in Thai.

\section{RESULTS AND DISCUSSION}

In this section, we first present and discuss findings for changes in attitudes towards science after presenting. This is followed by findings on interest in lifelong learning and whether attitudes and self-efficacy can predict lifelong learning. In these sections, we first consider findings for current presenters and, second, those for alumni presenters. There is a discussion of study limitations. We present conclusions and implications of the findings for future work.

\section{Changes in Attitudes About Science After Presenting Current Presenters}

Current presenters were asked their level of agreement with each statement on the 24 items of attitude scales before and after participation in the program. Paired-sample $t$-tests revealed the significant impact of presenting for all four subscales of the attitude scales (Table 4). Current presenters reported that they had increased Self-concept in science after their Science Caravan experience, indicating that the experience of presenting enabled self-perception of increased competence in science. Presenting with the Science Caravan offered opportunities to learn and acquire mastery through experience.

All of the high school students who presented were already studying science and most undergraduate students who presented were studying in STEM areas. As such, it was surprising that the scores for the pre-presenting "Future participation in science" scale were not as high as expected. This might be because two out of the four items in the scale relate to a specific career- "I would like to be a scientist" and "I would like to be a science teacher". Excluding these two items, the scores were higher for prepresenting $=3.77$ and post-presenting $=4.02$. Moreover, the perceived difficulty of science (Osborne et al., 2003) after taking some courses might be a factor in decisions not to continue to study science in the future. However, in the post-presenting, the current presenters reported increased positive intentions about participating in science in the future. This is consistent with answers from in-depth interviews that being a presenter confirmed the feeling about existing academic or career plans. For example,

I already liked science. Working in Science Caravan reaffirmed my feeling, it was right for me. Science is fun; therefore, I will study in science in the future.

[Current presenter, male, undergraduate]

We thought there might have been a ceiling effect for the Value of science to society scale, which had the highest mean score of all scales, both pre-presenting and post-presenting. Current presenters already had a highly positive attitude about the value of science before presenting at Science Caravan. This is consistent with a previous study which found positive public opinions in Thailand about science and technology (National Statistics Office of Thailand, 2008). Nonetheless, there was a significant, if small increase in positive attitudes about the Value of science to society after presenting.

It is interesting that, on average, current presenters "neither agree nor disagree" (mean $=3.08$ ) on the Anxiety about science presenting scale in the pre-presenting survey (Table 4). This 
might be because they had no experience regarding those items, for example, "It makes me anxious about how I will deal with questions from students". However, after their presenting experiences, respondents reported decreased Anxiety about science presenting in post-presenting. This indicates that the experience of presenting helped to reduce science anxiety when faced with a situation of explaining science to others. This is consistent with answers from in-depth interviews in that the value of feedback from NSM staff and visitors is likely to help reduce anxiety. For example,

At that time, a former director of [XXX] School, came in when I was about to pack up. He asked me a lot of questions. I answered him based on my knowledge while James (NSM staff) was there. He admired that I could solve specific problems well, making me feel good.

[Current presenter, female, undergraduate]

Although current presenters reported that they had less Anxiety about science presenting after their Science Caravan experience, the scores still indicated some Anxiety about science presenting. In interviews, some presenters explained that they felt they had insufficient knowledge regarding the exhibits. They reported that lack of sufficient knowledge made them feel nervous and anxious about explaining and answering questions from visitors. For example, a current presenter (male, high school student) said, "Sometimes I got questions when I did not have enough information, and I was afraid to give a wrong explanation.” A female high school student said "I was afraid that I could not explain to [visitors] well enough to make them understand, and answer the questions."

The anxiety of some presenters was exacerbated when they were asked questions by teachers, especially some that were very challenging. Anecdotal observations by the first author indicated that some teachers appeared to aim to show off their own knowledge to presenters or their students. This is not surprising given the context of a predominately didactic education system where teachers are expected to be the masters (Tatar and Horenczyk, 2000). Comments from two female current presenters were that: "Teachers asked me about in-depth details" (undergraduate student) and "Some teachers made me anxious" (high school student).

The current presenters experienced the feeling of being a significant person by providing an exciting science experience, as well as inspiring visitors about science, especially young school children who were the majority of visitors. The program provided an opportunity for presenters to obtain encouragement from visitors' positive feedback.

Attitudes can be developed from three elements-cognitive information, affective information, and behavioral information (Zanna and Rempel, 2008). The unique experience of presenting with the Science Caravan provided most presenters with a largely positive experience of explaining science to audiences, related to both affect and behavior. As a result, their attitudes towards science were more positive after presenting. As Olson and Zanna (1993) pointed out, a new affective experience can be a powerful source of influence, particularly for affect-based attitudes.

\section{Alumni Presenters}

Alumni presenters' responses showed the greatest effect of presenting for the scales Self-concept in science (Figure 2A) and the Value of science to society (Figure 2C), with approximately $80 \%$ of respondents reporting positive impact of their previous participation. Retrospective reporting of changes in Future participation in science showed a smaller change (Figure 2B). However, a still high $70 \%$ of respondents reported that their feeling about a continued future participation in science areas was much or a little improved, while $24 \%$ of respondents felt it was about the same after presenting.

Even though half of the respondents reported that they had less Anxiety about science presenting, this scale had the smallest percentage change when compared to the other three scales (Figure 2D). A quarter of respondents rated "about the same" in anxiety about science presenting and approximately a quarter felt increased anxiety. These results were consistent with the results from the current presenters that their anxiety about science presenting still existed after the 6 days of their experience with the program.

Alumni comments in the end of the survey indicated that participants valued their experience as a presenter. For example: "It was worthwhile being a presenter" [Alumni presenter, female], and "I was so proud and happy working with the Science Caravan" [Alumni presenter, male].

\section{Changes in Female and Male Participants' Attitudes Towards Science}

There was a significant interaction between gender and the presenting intervention in relation to Anxiety about science presenting (Table 5). While being presenters resulted in reports of lower levels of Anxiety about science presenting for both male and female students, there was a greater effect for female presenters who had a less negative attitude on the Anxiety about science presenting scale after their experience (Figure 3 ). The 6 days of experience presenting with the Science Caravan had a larger impact for female presenters than their male counterparts in fostering self-confidence in science presentation and reducing their anxiety about science presenting.

There were significant main effects of gender and of presenting for Future participation in science, but no interaction effect (Table 5). There was no significant difference in this scale between men and women before their involvement as a program presenter; however, after contributing as a program presenter, women had more positive response in Future participation in science than men, $t(688)=2.26, p<0.05$.

Alumni male presenters reported a higher Self-concept in science than female presenters and both reported higher Selfconcept in science (4.1-4.2) than did current presenters postpresenting (3.7-3.8). In the long-term period, there was no significant difference between male and female alumni 

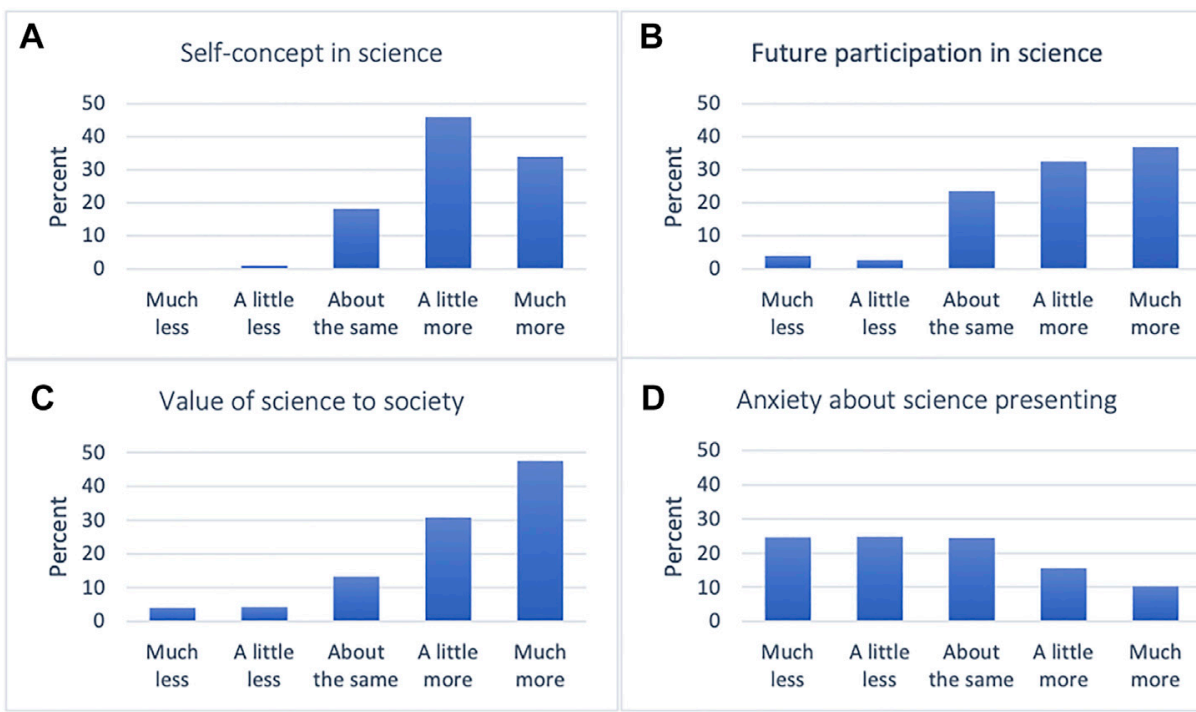

D Anxiety about science presenting

FIGURE 2 | Alumni presenters' retrospective rating (percentage; $n=678$ ) of how being a presenter had impacted their attitudes towards science in four scales: Self-concept in science (A); Future participation in science (B); Value of science to society (C); and Anxiety about science presenting (D).

\begin{tabular}{|c|c|c|c|c|c|c|}
\hline Scale & Df & Mean square & $\boldsymbol{F}$ & Sig. & Effect size & $R^{2}$ \\
\hline \multicolumn{7}{|c|}{ 1) Self-concept in science (7 items) } \\
\hline Gender & 1 & 17.75 & 1.52 & 0.218 & 0.001 & - \\
\hline Intervention*Gender & 1 & 15.32 & 1.31 & 0.253 & 0.001 & 0.071 \\
\hline Error & 1,376 & 11.7 & - & - & - & - \\
\hline Gender & 1 & 33.12 & 2.52 & 0.112 & 0.002 & - \\
\hline Intervention*Gender & 1 & 3.39 & 0.26 & 0.611 & 0 & 0.02 \\
\hline Error & 1,376 & 13.13 & - & - & - & - \\
\hline \multicolumn{7}{|c|}{ 3) Future participations (4 items) } \\
\hline Intervention & 1 & 159.13 & $22.55^{\star \star \star}$ & 0.000 & 0.016 & - \\
\hline Gender & 1 & 48.07 & $6.81^{\star \star}$ & 0.009 & 0.005 & - \\
\hline Intervention*Gender & 1 & 2.56 & 0.36 & 0.547 & 0 & 0.024 \\
\hline Intervention*Gender & 1 & 58.03 & $4.11^{*}$ & 0.043 & 0.003 & 0.051 \\
\hline Error & 1,376 & 14.12 & - & - & - & - \\
\hline
\end{tabular}

N.B.: ${ }^{*} \mathrm{p}<0.05,{ }^{* *} \mathrm{p}<0.01,{ }^{* * *} \mathrm{p}<0.001$

presenters in their attitudes about science for the other three attitude scales.

\section{Increased Interest in Lifelong Learning Activities After Presenting \\ Current Presenters}

After presenting, there was a significant increase in current presenters' interest in most of the listed science-related activities in their free time, $z=8.78, p<0.001, d=0.76$

(Figure 4). Among science-related activities, "Browsing updated science news" showed the highest increase in respondents' interest.

In contrast, there was a decrease on intention to Visit science museum, science center, zoo and Watching science documentary or TV show, $z=2.32, p<0.05, d=0.19$. Given presenters had just spent an intensive week in a travelling science center, it could be their interest was sated and their focus shifted to different activities. It is interesting to note that presenters studying with a science major changed their preferences for obtaining science knowledge. They were more likely to favor active learning seeking science knowledge 


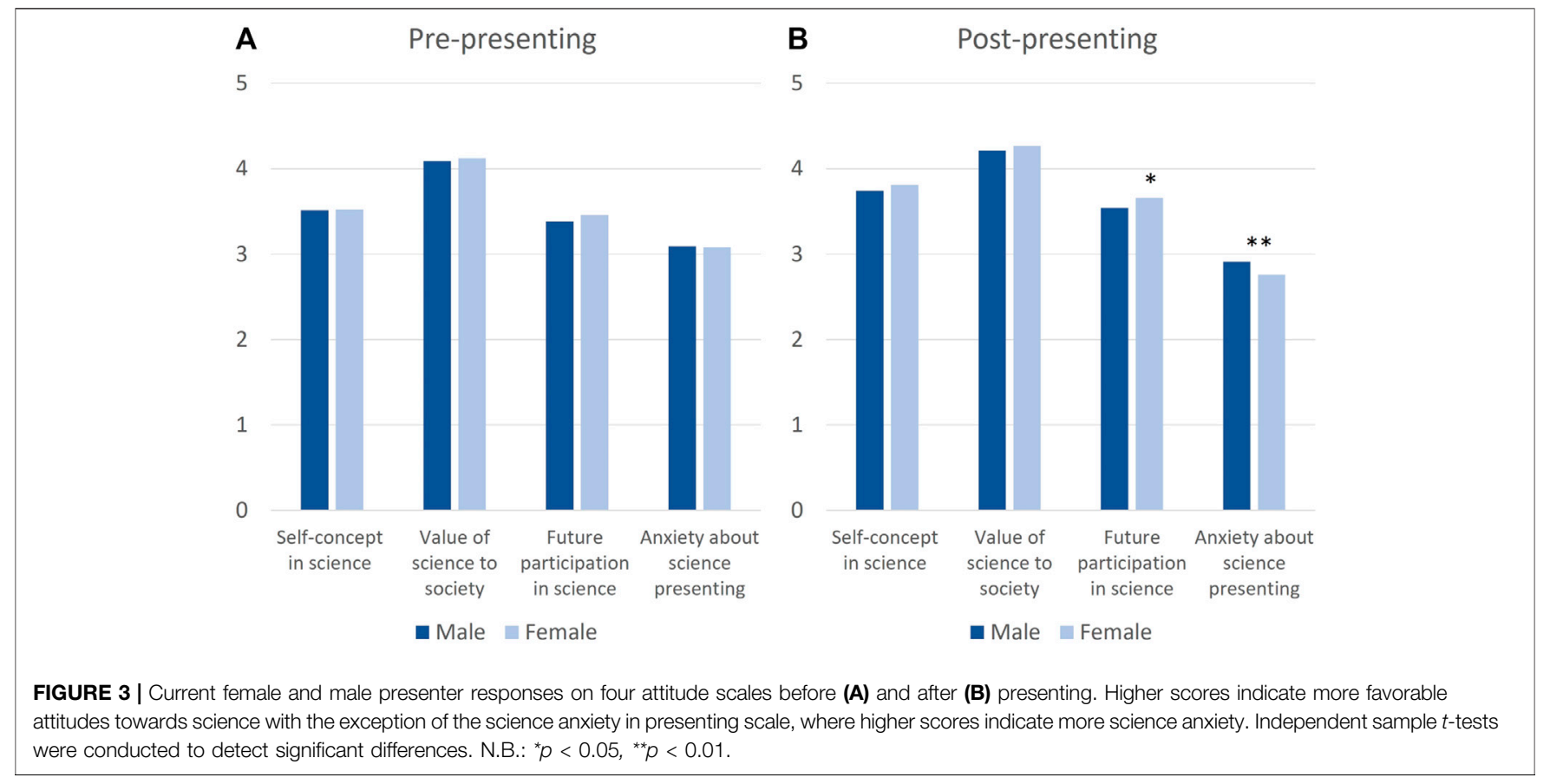

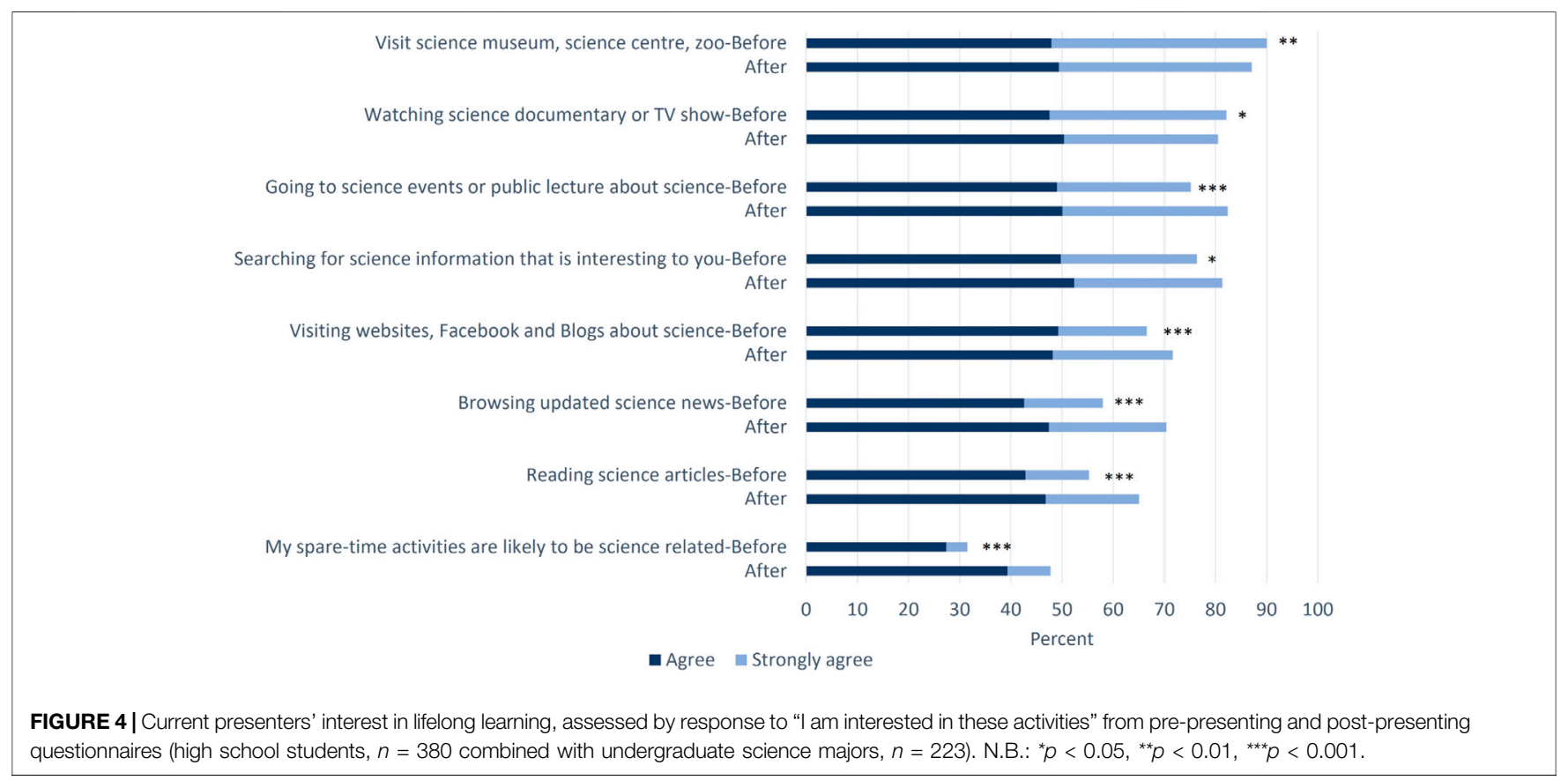

that is of interest to them rather than passive learning, receiving information by watching science documentaries and TV shows, or visiting science museums. Although their interest in these activities significantly decreased, over $80 \%$ of respondents rated these items highly in both the prepresenting and post-presenting surveys.

\section{Alumni Presenters}

In contrast to current presenters, over $90 \%$ of alumni presenters reported increases in their interest to Visit science museum, science center, zoo (Figure 5). In addition, over $75 \%$ of respondents agreed that they were more interested in all of the listed lifelong learning activities. Almost half of respondents agreed that presenting 


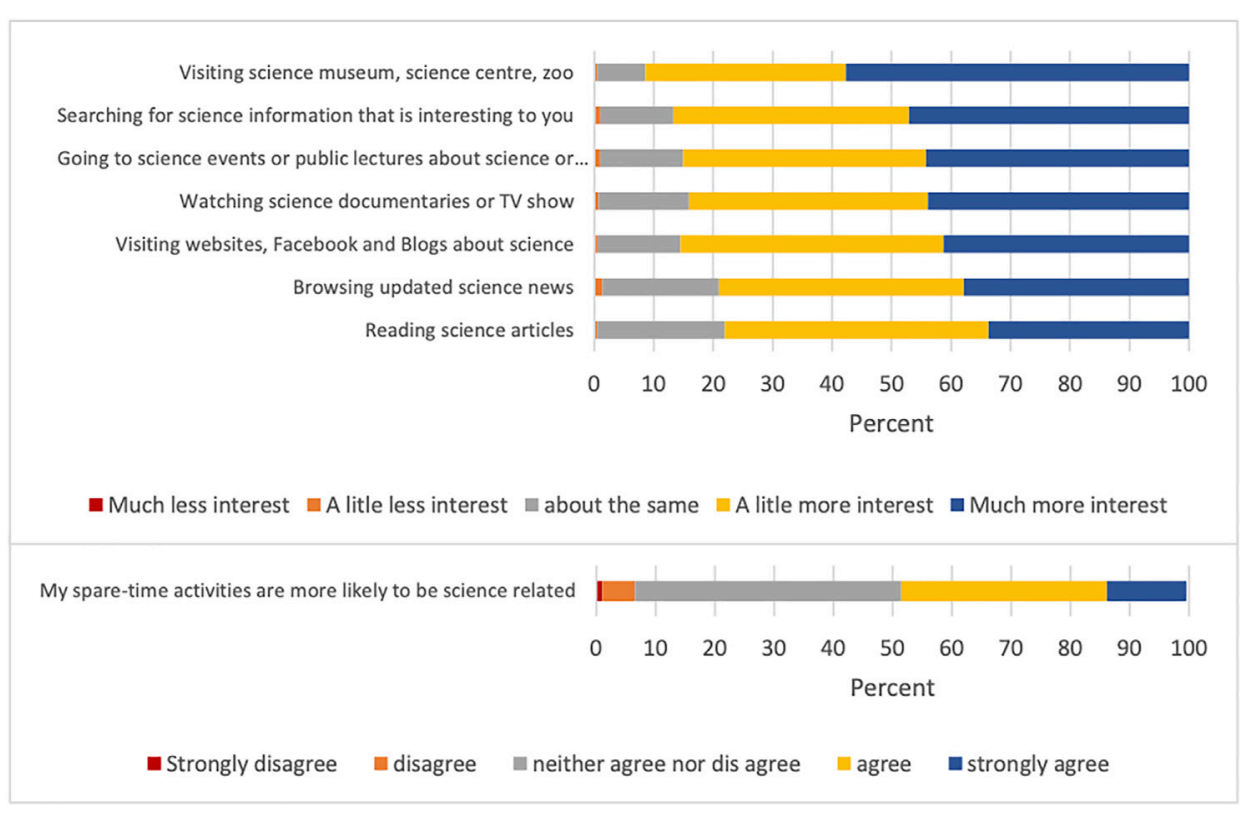

FIGURE 5 | Alumni presenters' views on impact of presenting on their interest in lifelong learning activities in science.

increased their inclination for spare time activities related to science, indicating that many respondents expected to maintain interest in ongoing engagement with science-related activities.

\section{Qualitative Findings for Both Groups}

The qualitative findings are consistent with the quantitative results, which provide clear evidence that participation in presenting enhanced interest in science-related activities for both current and alumni presenters. For example, one current presenter said:

In my free time, I liked to watch movies. After being a presenter, I am more curious. It changed me from watching movies to watching documentaries about science instead. I already liked to watch documentaries about animals. Being a presenter inspired me to learn more. [I] got more curious about science.

[Current presenter, female, undergraduate]

Furthermore, results from alumni presenters confirmed that they were still interested in the science-related activities up to 10 years after their experience of presenting. For example:

I am interested in many leisure activities. If speaking of science-related activities, I like to read research articles about physics on websites and follow up all about science and technology updates. Because I love to know about the advancement of technology, and I want to update my knowledge.

[Alumni presenter, male, undergraduate]
The quotes above indicate that presenters maintain lifelong learning behaviors related to science. The results support Hidi and Renninger (2006), that people engage with an object of their interest after interaction between the person and relevant content. According to Hidi and Renninger (2006), interest is “a motivational variable that refers to a psychological state of engaging or the predisposition to reengage with particular classes of objects, events, or ideas over time" (p. 112). People have their interest triggered when experience catches their attention (Renninger and Bachrach, 2015). One explanation may be that the positive, novel experience of being a presenter triggered their interest in science-related activities. In addition, the new experience with positive feelings enhanced presenters' self-concept in science. There is a feedback loop as positive feelings can influence the development of interest, and interest shapes self-concept (Hannover, 1998 cited in; Wender, 2004).

\section{Attitudes towards Science and Self-Efficacy as Predictors of Lifelong Learning Behavior} As discussed earlier, the Theory of Planned Behavior (Ajzen, 1991) states that an individual's intention is a predictor of engaging in a behavior, and that this intention is influenced by attitudes towards the behavior, subjective norm, and perceived behavioral control. According to Ajzen (2002), the concept of perceived behavioral control aligns with the notion of selfefficacy. It was predicted that two influencing constructs would be impacted by the presenting experiences: Attitudes towards science and Self-efficacy in science knowledge. Hierarchical multiple regression used these two constructs, 

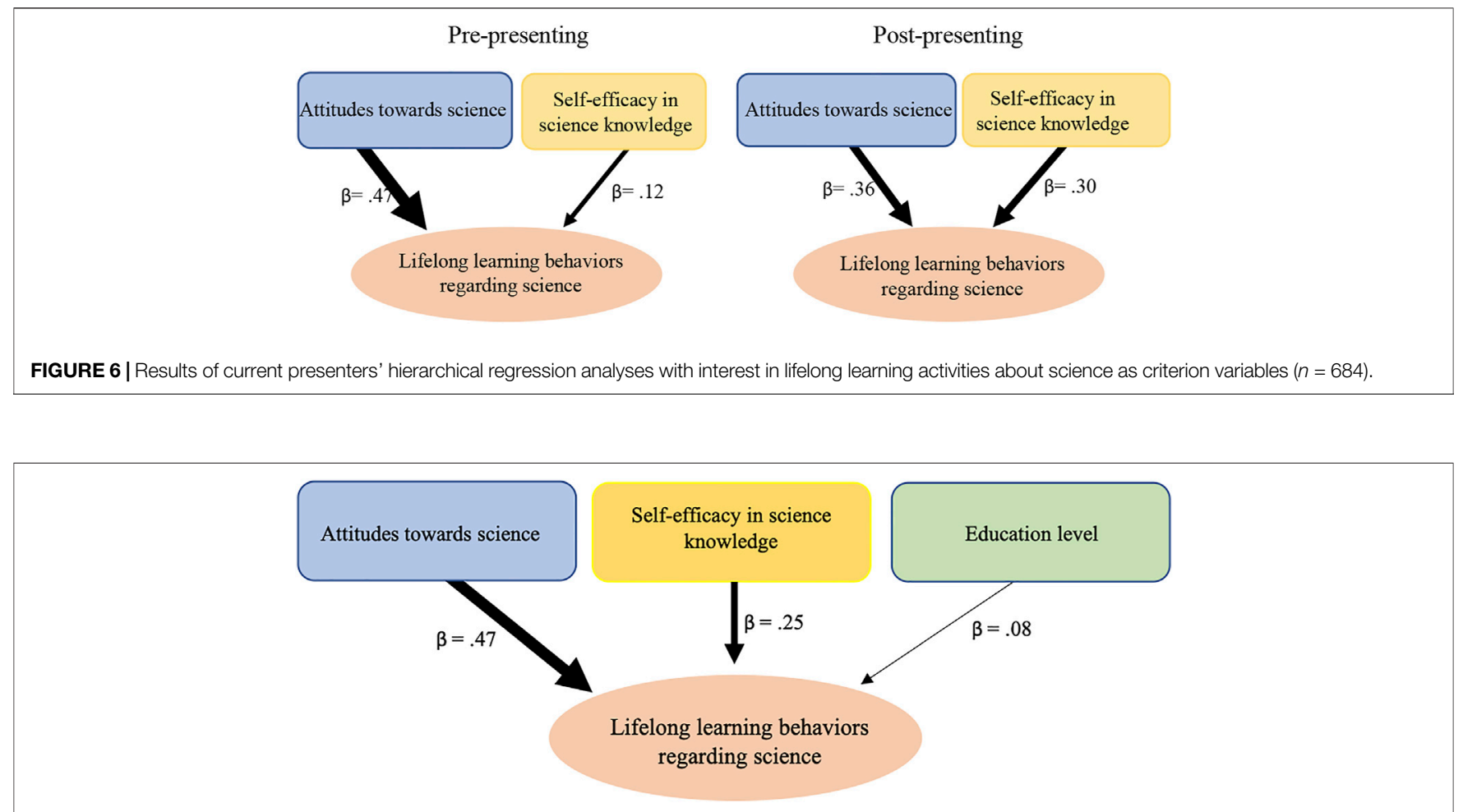

FIGURE 7 | Alumni presenters' hierarchical regression analyses with lifelong learning behaviors regarding science as criterion variables $(n=678)$.

gender and education level as variables to predict the impact of contribution as a presenter on behaviors related to Lifelong learning about science.

\section{Current Presenters}

In the pre-presenting survey, Attitudes towards science, as measured in this study's scales, made the strongest unique contribution to explaining intention for Lifelong learning about science with current presenters, demonstrated by hierarchical multiple regression (Figure 6). The relationship was positive; those having positive feelings in Attitudes towards science and Self-efficacy in science knowledge while being presenters were more likely to intend to practice lifelong learning behaviors related to science. Gender and education level were entered at step 1, explaining $0.4 \%$ of the variance in Lifelong learning behavior about science. After entry of the Attitudes towards science, and Self-efficacy in science knowledge at step 2, the total variance explained by the model as a whole was $28 \%$, $F(4,678)=66.17, p<0.001$. The two constructs explained an additional $27.7 \%$ of the variance in Lifelong learning about science, after controlling for gender and education level $\left[R^{2}\right.$ change $=0.28, F$ change $(2,678)=130.51, p<0.001]$. In the final model, two constructs were statistically significant, with Attitudes towards science being a better predictor (beta $=0.47, p<$ 0.001 ) than Self-efficacy in science knowledge (beta $=0.12, p=$ $0.001)$.

In the post-presenting survey, hierarchical multiple regression of results from current presenters revealed similar results to those pre-presenting (see Figure 6). The proposed model yields two significant variables explaining $32 \%$ of variance of Lifelong learning about science $[F(4,677)$ $=79.39, p<0.001]$. Again, attitudes towards science was the strongest predictor (beta $=0.36, p<0.001$ ), followed by Selfefficacy in science knowledge (beta $=0.30, p<0.001$ ). In the post-presenting results, Self-efficacy in science knowledge was a stronger predictor than in the pre-presenting results. This suggests that increase of positive Self-efficacy in science knowledge after presenting added to the ability of this construct to predict behavioral intention towards lifelong learning in science.

\section{Alumni Presenters}

Alumni presenters' experiences of presenting had long-term impacts on their self-reported actual lifelong learning behavior (see Figure 7). The proposed model yields three significant predictors explaining $38 \%$ of the variance of lifelong learning behavior scores $[F(4,671)=103.55, p<0.001]$. Attitudes towards science was the strongest predictor (beta $=0.47, p<0.001$ ) followed by Self-efficacy in science knowledge (beta $=0.25, p<$ 0.001 ). Education level was a third, weak predictor, unlike in the model for current presenters, where no significant effect of education level on prediction was found. The direction of the relationship suggests that having more positive feelings regarding Attitudes towards science, Self-efficacy in science knowledge, and lower education level (younger age) as a presenter significantly contributed to intentions towards lifelong learning behaviors. 
Attitudes towards science form from integration of experiences with various aspects of science (Gardner, 1975; Bennett, 2003). Attitudes one holds as a result of these experiences may influence subsequent decisions and behaviors (Bennett, 2003). People have their interest triggered when an experience focuses their attention (Renninger and Bachrach, 2015). One possible explanation of increased interest in lifelong learning behavior noted by presenters in Science Caravan was the development of interest from positive feelings. Interest shapes selfconcept (Hannover, 1998, cited in Wender, 2004). The results from alumni presenters support findings of Hidi and Renninger (2006) that interaction with particular content sparks students' engagment with an object of interest.

\section{Study Limitations}

This study had several limitations. Firstly, the findings are based on self-reports. Secondly, while all current presenters responded to the surveys ( $100 \%$ response rate), only 726 out of 8,000 alumni presenters completed the alumni survey (9.1\%), indicating the potential for sample bias in responses of alumni presenters. Because there was no contact list of alumni presenters, it was impossible to contact them more directly. Facebook pages: คาราวานวิทยาศาสตร (Science Caravan), and Enjoy Science Career page were the primary avenues to reach alumni presenters and recruit participants. It seems likely that alumni presenters following these pages hold more favorable opinions about the Science Caravan program. These alumni presenters may have been more diligent in maintaining contact with the program and staff, and more receptive to responding to a survey about the program. This is an important consideration in determining potential bias (Sickler and Johnson, 2009), as are the characteristics of non-respondents (Robson, 2011).

Further indication of a biased sample of alumni presenters is that unlike current presenters, all alumni presenters who responded to the survey were involved in science studies or careers. Therefore, a long-term impact of participating in Science Caravan on presenters who had not been studying science could not be examined in this study. There was no negative feedback about the program obtained from respondents. While there was no evidence to indicate that the non-responding alumni had more negative perspectives, a conservative view would assume that the overall impact on all alumni presenters may not be as strong as the results reported in this study. Nonetheless, response from current presenters included non-science students who reported positive impacts of presenting.

\section{CONCLUSION}

There are many studies about attitudes of audience members after outreach programs or visiting an informal setting environment (Mamlok-Naaman et al., 2005; Luehmann, 2009; Salmi et al., 2016; Yawson et al., 2016; Vennix et al., 2018). Research investigating presenters' attitudes through participation in outreach activities is more limited (Larsen, 1994; Ferry, 1995; Toolin, 2003). This paper reports impacts of participation as a presenter in Science Caravan on attitudes to science and behavioral intentions for lifelong learning.
Both current and alumni presenters at Science Caravan reported positive impacts of their participation as presenters on their attitudes towards science. Attitudes were measured using four scales: Future participation in science, Self-concept in science, Value of science to society, and Anxiety about science presenting. Results of the pre-presenting surveys demonstrate that current presenters already possessed positive attitudes towards science. These findings are consistent with the results from previous surveys that have shown that many in Thailand are knowledgeable and positive about the importance of science and technology, even if they make a decision not to study science or take on scientific careers (National Statistics Office of Thailand, 2008; Yuenyong and Narjaikaew, 2009). Nevertheless, the brief experience of being Science Caravan presenters had positive effects in all four scales of science attitudes. This demonstrates that an intensive 6-day outreach experience can increase positive attitudes towards science.

Changes in behavioral intentions related to lifelong learning were investigated in this study. When asked about their interest in daily spare-time activities related to science, current presenters agreed that they were more interested in many activities related to lifelong learning after the 6-day program. Results from alumni presenters confirmed that they still felt more interested in the science-related lifelong learning activities years after presenting, providing evidence of an actual change in behavior, albeit selfreported and retrospective.

The results of this study demonstrate the value of using the Theory of Planned Behavior to explore science outreach. Attitudes towards science and self-efficacy were measured in this research. In this study, students were more likely to choose to continue to engage in science-related activities in their spare time when they reported feeling competent and having positive attitudes towards science. There is a positive relationship between attitudes towards science, self-efficacy and interest, and these lead to choosing science-related activities in lifelong learning. Future research could examine the effect of the subjective norm as another important factor that influences behavioral intention in the Science Caravan context.

This study provides evidence of a positive relationship between attitudes towards science and interest in spare-time science activities. The development of positive attitudes towards science can motivate students' interest in science education and science-related careers (Crawley and Coe, 1990; Norwich and Duncan, 1990). Interest is a psychological construct that can be used to predict an intention to participate in sciencerelated activities in the future (Ainley and Ainley, 2011). We suggest that an increase of students' interest and participation in science activities in their spare time can lead to an increase of intended lifelong learning behavior about science. Several studies have found that interest is an important factor for choices of education and occupations in STEM areas (Venville et al., 2010; Bøe, 2012; Venville et al., 2013). This study revealed that presenters' experience with Science Caravan provided a valuable experience that helped them to develop interest related to science. Furthermore, this study revealed that presenters' positive attitudes towards science could be developed by a short-term, intensive experience as a presenter. 


\section{Implications and Future Research}

The outreach learning atmosphere and experience was perceived positively by volunteer presenters. We suggest that educators, teachers, and schools should consider adding presentation and science outreach activities to their curriculum. In particular, activities with an out-of-school experiential learning element could be especially valuable supplements to curriculum for science students and pre-service teachers. The activities should enable performance and mastery of experience for the students, focusing on the understanding and application of science, connecting to the curriculum and daily life.

Findings from this study support the value of involvement of science undergraduate students in the delivery of public engagement activities. This aligns with findings of Mackay et al. (2020); as public engagement should be the business of all scientists, this approach would help to ensure that more budding scientists are adequately prepared to engage with the public about science using diverse and effective techniques. In order to ensure that science communication training and practice is offered to trainee scientists, we recommend that informal science learning institutes and universities cooperate to develop and offer programs in this area to their students.

Future research could determine the proportion of presenters continuing study in science-related disciplines in higher education. Although this study used surveys and interviews of alumni presenters to investigate the longer-term impact of the program, a longitudinal study was not within its scope. As mentioned above, the distribution of an online questionnaire survey to alumni presenters via Facebook is likely to have introduced sample bias. None of the non-science alumni presenters responded to the survey. A longitudinal design could examine the longer-term impact of contributing as a presenter with the Science Caravan program.

Research has pointed out that "attitudes toward science change with exposure to science, but that the direction of change may be related to the quality of that exposure" (Gogolin and Swartz, 1992, p. 500). This study offers evidence that there is a positive relationship between attitudes towards science and interest in science activities, indicating that Science Caravan provides quality exposure.

Many studies about outreach programs have shown that science outreach activities can positively influence visitors' attitudes and motivation (Bell et al., 2009). Far fewer have

\section{REFERENCES}

Ainley, M., and Ainley, J. (2011). Student Engagement with Science in Early Adolescence: The Contribution of Enjoyment to Students' Continuing Interest in Learning about Science. Contemp. Educ. Psychol. 36 (1), 4-12. doi:10.1016/j. cedpsych.2010.08.001

Ajzen, I., and Driver, B. L. (1992). Application of the Theory of Planned Behavior to Leisure Choice. J. Leis. Res. 24 (3), 207-224. doi:10.1080/00222216.1992.11969889

Ajzen, I. (1985). "From Intentions to Actions: A Theory of Planned Behavior," in Action Control. SSSP Springer Series in Social Psychology. Editors J. Kuhl and J. Beckmann (Berlin, Heidelberg: Springer), 11-39. doi:10.1007/978-3-642-69746-3_2

Ajzen, I. (1991). The Theory of Planned Behavior. Organ. Behav. Hum. Decis. Process. 50 (2), 179-211. doi:10.1016/0749-5978(91)90020-t examined impact on presenters. This report is a significant contribution in that respect. This study demonstrates that a short-term, intensive experience of presenting with Science Caravan provided a valuable experience that helped presenters develop more positive attitudes towards science and increased their intentions of future participation in lifelong learning about science.

\section{DATA AVAILABILITY STATEMENT}

The raw data supporting the conclusion of this article will be made available by the authors, without undue reservation.

\section{ETHICS STATEMENT}

The studies involving human participants were reviewed and approved by The Human Research Ethics Committee of the University of Otago, New Zealand (Reference 17/116). Written informed consent from the participants' legal guardian/next of kin was not required to participate in this study in accordance with the national legislation and the institutional requirements.

\section{AUTHOR CONTRIBUTIONS}

NS, NL, and RS-S contributed to conception and design of the study. NS organized the database, performed the statistical analysis, and wrote the first draft of the manuscript. All authors contributed to manuscript revision, read, and approved the submitted version.

\section{ACKNOWLEDGMENTS}

The first author was recipient of a Royal Thai Government Scholarship. We thank the Thai government, the National Science Museum, Thailand, and the Centre for Science Communication, University of Otago, New Zealand, for support. A huge thank you to all the presenters who agreed to participate in this research and to fellow science communicators and researchers who provided feedback at every stage of this study.

Ajzen, I. (2002). Perceived Behavioral Control, Self-Efficacy, Locus of Control, and the Theory of Planned Behavior1. J. Appl. Soc. Psychol. 32 (4), 665-683. doi:10. 1111/j.1559-1816.2002.tb00236.x

Bandura, A. (1986). Social Foundations of Thought and Action: A Social Cognitive Theory. Englewood Cliffs, N.J: Prentice-Hall.

Bell, P., Lewenstein, B., Shouse, A. W., and Feder, M. A. (2009). Learning Science in Informal Environments: People, Places and Pursuits. Washington, DC: National Academies Press.

Bennett, J. (2003). Teaching and Learning Science: A Guide to Recent Research and its Applications. New York: A \& C Black.

Bøe, M. V. (2012). Science Choices in Norwegian Upper Secondary School: What Matters? Sci. Educ. 96 (1), 1-20. doi:10.1002/sce.20461

Chalamwong, Y., and Pomlakthong, N. (2004). A Study of Relationship of Manpower Requirement in Industries with Education Supply. Bangkok: Thailand Development Research Institute TDRI. 
Cobern, W. W. (2015). The Lifelong Learning of Science. Ijlel 1 (1), 1-10. doi:10. 25233/ijlel/2015-v1ilp1

Crawley, F. E., and Coe, A. S. (1990). Determinants of Middle School Students' Intention to Enroll in a High School Science Course: An Application of the Theory of Reasoned Action. J. Res. Sci. Teach. 27, 461-476. doi:10.1002/tea. 3660270506

Daniel, B. K., and Harland, T. (2018). Higher Education Research Methodology: A Step-by-step Guide to the Research Process. Abingdon, Oxon New York, NY: Routledge.

European Commission (2001). Making a European Area of Lifelong Learning a Reality. Brussels, Belgium: Commission of the European Communities.

Ferry, B. (1995). Science Centers in Australia Provide Valuable Training for Preservice Teachers. J. Sci. Educ. Technol. 4 (3), 255-260. doi:10.1007/ bf02211840

Fleiss, J. L., Levin, B., and Paik, M. C. (2003). Statistical Methods for Rates and Proportions. 3rd ed. Hoboken, NJ: Wiley.

Frey, B. B. (2018). The SAGE Encyclopedia of Educational Research, Measurement, and Evaluation, 1-4. Thousand Oaks, CA: SAGE Publications, Inc. doi:10.4135/ 9781506326139

Gardner, P. L. (1975). Attitudes to Science : A Review. Stud. Sci. Educ. 2, 1-41. doi:10.1080/03057267508559818

Gibson, H. L., and Chase, C. (2002). Longitudinal Impact of an Inquiry-Based Science Program on Middle School Students' Attitudes toward Science. Sci. Ed. 86 (5), 693-705. doi:10.1002/sce.10039

Gogolin, L., and Swartz, F. (1992). A Quantitative and Qualitative Inquiry into the Attitudes toward Science of Nonscience College Students. J. Res. Sci. Teach. 29 (5), 487-504. doi:10.1002/tea.3660290505

Guest, G. (2013). Describing Mixed Methods Research. J. Mixed Methods Res. 7 (2), 141-151. doi:10.1177/1558689812461179

Hannover, B. (1998). "The Development of Self-Concept and Interests," in Interest and Learning: Proceedings of the Seeon Conference on Interest and Gender. (Editors) A. Hoffmann, A. Krapp, K. A. Renninger, and J. Renninger. (Kiel, Germany: IPN), 105-125.

Hidi, S., and Renninger, K. A. (2006). The Four-phase Model of Interest Development. Educ. Psychol. 41 (2), 111-127. doi:10.1207/s15326985ep4102_4

Hillman, S. J., Zeeman, S. I., Tilburg, C. E., and List, H. E. (2016). My Attitudes toward Science (MATS): the Development of a Multidimensional Instrument Measuring Students' Science Attitudes. Learn. Environ. Res. 19 (2), 203-219. doi:10.1007/s10984-016-9205-x

Jones, M. G., Corin, E. N., Andre, T., Childers, G. M., and Stevens, V. (2017). Factors Contributing to Lifelong Science Learning: Amateur Astronomers and Birders. J. Res. Sci. Teach. 54 (3), 412-433. doi:10.1002/tea.21371

Kawamoto, S., Nakayama, M., and Saijo, M. (2013). A Survey of Scientific Literacy to Provide a Foundation for Designing Science Communication in Japan. Public Underst Sci. 22 (6), 674-690. doi:10.1177/0963662511418893

Kind, P., Jones, K., and Barmby, P. (2007). Developing Attitudes towards Science Measures. Int. J. Sci. Educ. 29 (7), 871-893. doi:10.1080/09500690600909091

Kong, X., Dabney, K. P., and Tai, R. H. (2014). The Association between Science Summer Camps and Career Interest in Science and Engineering. Int. J. Sci. Educ. B 4 (1), 54-65. doi:10.1080/21548455.2012.760856

Kouthouris, C., and Spontis, A. (2005). Outdoor Recreation Participation: an Application of the Theory of Planned Behavior. Sport J. 8 (3). unpaginated.

Kvale, S., and Brinkmann, S. (2009). Interviews: Learning the Craft of Qualitative Research Interviewing. Los Angeles: SAGE Publications Inc.

Laerd Statistics (2019). Fleiss' Kappa Using SPSS Statistics. Statistical tutorials and software guides. Available from: https://statistics.laerd.com/spss-tuorials/fleisskappa-in-spss-statistics.php (Retrieved August 19, 2020).

Larsen, J. I. (1994). Influences Reported by Adolescent Museum Demonstrators in the Areas of Communication Skills, Self-Image, and Approach to Science. Cincinatti, Ohio: University of Cincinnati.

Laursen, S., Liston, C., Thiry, H., and Graf, J. (2007). What Good Is a Scientist in the Classroom? Participant Outcomes and Program Design Features for a Short-Duration Science Outreach Intervention in K-12 Classrooms. CBE Life Sci. Educ. 6 (1), 49-64. doi:10.1187/cbe.06-05-0165

Lent, R. W., Sheu, H.-B., Singley, D., Schmidt, J. A., Schmidt, L. C., and Gloster, C. S. (2008). Longitudinal Relations of Self-Efficacy to Outcome Expectations, Interests, and Major Choice Goals in Engineering Students. J. Vocational Behav. 73 (2), 328-335. doi:10.1016/j.jvb.2008.07.005
Lin, P.-Y., and Schunn, C. D. (2016). The Dimensions and Impact of Informal Science Learning Experiences on Middle Schoolers' Attitudes and Abilities in Science. Int. J. Sci. Educ. 38 (17), 2551-2572. doi:10.1080/09500693.2016. 1251631

Longnecker, N. (2016). An Integrated Model of Science Communication More Than Providing Evidence. Jcom 15 (05), Y01-Y13. doi:10.22323/2. 15050401

Luehmann, A. L. (2009). Students' Perspectives of a Science Enrichment Programme: Out-of-school Inquiry as Access. Int. J. Sci. Educ. 31 (13), 1831-1855. doi:10.1080/09500690802354195

Mackay, S. M., Tan, E. W., and Warren, D. S. (2020). Developing a New Generation of Scientist Communicators through Effective Public Outreach. Commun. Chem. 3 (1), 1-9. doi:10.1038/s42004-020-0315-0

Mamlok-Naaman, R., Ben-Zvi, R., Hofstein, A., Menis, J., and Erduran, S. (2005). Learning Science through a Historical Approach: Does it Affect the Attitudes of Non-Science-Oriented Students towards Science? Int. J. Sci. Math. Educ. 3 (3), 485-507. doi:10.1007/s10763-005-0696-7

McHugh, M. L. (2012). Interrater Reliability: the Kappa Statistic. Biochem. Med. (Zagreb) 22 (3), 276-282. doi:10.11613/bm.2012.031

National Statistics Office of Thailand (2008). Basic Statistics Report on the Situation of the Country. Available from: http://service.nso.go.th/nso/ nsopublish/pubs/ebook/base_GOV/index.html (Accessed September 13, 2019).

Norwich, B., and Duncan, J. (1990). Attitudes, Subjective Norm, Perceived Preventive Factors, Intentions and Learning Science: Testing a Modified Theory of Reasoned Action. Br. J. Educ. Psychol. 60, 312-321. doi:10.1111/j. 2044-8279.1990.tb00947.x

O'Leary, Z. (2010). The Essential Guide to Doing Your Research Project. London: SAGE Publications.

Olson, J. M., and Zanna, M. P. (1993). Attitudes and Attitude Change. Annu. Rev. Psychol. 44 (1), 117-154. doi:10.1146/annurev.ps.44.020193.001001

Osborne, J., Simon, S., and Collins, S. (2003). Attitudes towards Science: A Review of the Literature and its Implications. Int. J. Sci. Educ. 25 (9), 1049-1079. doi:10. 1080/0950069032000032199

Pallant, J. (2011). SPSS Survival Manual 4th Edition: A Step by Step Guide to Data Analysis Using SPSS Version 18. Maidenhead, Berkshire: Open University Press. Retrieved on from: http://www.allenandunwin.com/spss.

Rajala, A., Kumpulainen, K., Hilppö, J., Paananen, M., and Lipponen, L. (2016). "Connecting Learning across School and Out-Of-School Contexts: A review of Pedagogical Approaches," in Learning across Contexts in the Knowledge Society (Brill Sense), 15-35. doi:10.1007/978-94-6300-414-5_2

Renninger, K. A., and Bachrach, J. E. (2015). Studying Triggers for Interest and Engagement Using Observational Methods. Educ. Psychol. 50 (1), 58-69. doi:10.1080/00461520.2014.999920

Robson, C. (2011). Real World Research, Vol. 3. Chichester: Wiley.

Salmi, H., Thuneberg, H., and Vainikainen, M.-P. (2016). How Do Engineering Attitudes Vary by Gender and Motivation? Attractiveness of Outreach Science Exhibitions in Four Countries. Eur. J. Eng. Educ. 41 (6), 638-659. doi:10.1080/ 03043797.2015.1121466

Sawilowsky, S. S. (2009). New Effect Size Rules of Thumb. J. Mod. App. Stat. Meth. 8 (2), 597-599. doi:10.22237/jmasm/1257035100

Sickler, J., and Johnson, E. (2009). New York Hall of Science: Science Career Ladder Retrospective Impact Study. Edgewater, MD: Institute for Learning Innovation. Retrieved from: https://www.informalscience.org/sites/default/files/SCL Alumni_Report_-_FINAL_-_2009_08_12.pdf.

Sripaoraya, N. (2020). Participation in Science Outreach and its Impact on Programme Presenters. Dunedin, New Zealand: University of Otago. Doctoral dissertation.

Tatar, M., and Horenczyk, G. (2000). Parental Expectations of Their Adolescents' Teachers. J. Adolesc. 23 (4), 487-495. doi:10.1006/jado.2000.0333

Tavakol, M., and Dennick, R. (2011). Making Sense of Cronbach's Alpha. Int. J. Med. Educ. 2, 53-55. doi:10.5116/ijme.4dfb.8dfd

Toolin, R. E. (2003). Learning what it Takes to Teach Science: High School Students as Science Teachers for Middle School Students. J. Sci. Educ. Technol. 12 (4), 457-469. doi:10.1023/b:jost.0000006305.73229.5c

Triyarat, W. (2017). Factors Affecting Engagement with Informal Science Learning in Thailand: A Regional Perspective. Doctoral dissertation. Bristol (England): University of the West of England. 
Tuijnman, A., and Boström, A. K. (2002). Changing Notions of Lifelong Education and Lifelong Learning. Int. Rev. Educ. 48 (1-2), 93-110. doi:10.1023/a: 1015601909731

Vennix, J., den Brok, P., and Taconis, R. (2018). Do outreach Activities in Secondary STEM Education Motivate Students and Improve Their Attitudes towards STEM? Int. J. Sci. Educ. 40 (11), 1263-1283. doi:10.1080/09500693. 2018.1473659

Venville, G., Oliver, M., Longnecker, N., and Rennie, L. (2010). Selecting Science Subjects: Why Students Do, Why They Can't!. Teach. Sci. 56 (3), 19-25. doi:10. 3316/aeipt.184048

Venville, G., Rennie, L., Hanbury, C., and Longnecker, N. (2013). Scientists Reflect on Why They Chose to Study Science. Res. Sci. Educ. 43 (6), 2207-2233. doi:10. 1007/s11165-013-9352-3

Weinburgh, M. E., and Steele, D. (2000). The Modified Attitudes toward Science Inventory: Developing an Instrument to Be Used with Fifth Grade Urban Students. J. Women Minorities Sci. Eng. 6 (1), 87-94. doi:10.1615/ jwomenminorscieneng.v6.i1.50

Wender, I. (2004). Relation of Technology, Science, Self-Concept, Interest, and Gender. J. Technol. Stud. 30 (3), 43-51. doi:10.21061/jots.v30i3.a.7

Yawson, N. A., Amankwaa, A. O., Tali, B., Shang, V. O., Batu, E. N., Asiemoah, K., et al. (2016). Evaluation of Changes in Ghanaian Students' Attitudes towards Science Following Neuroscience Outreach Activities: A Means to Identify Effective Ways to Inspire Interest in Science Careers. J. Undergrad Neurosci. Educ. 14 (2), A117-A123.
Yuenyong, C., and Narjaikaew, P. (2009). Scientific Literacy and Thailand Science Education. Int. J. Environ. Sci. Educ. 4 (3), 335-349.

Zanna, M. P., and Rempel, J. K. (2008). "Attitudes: A New Look at an Old Concept," in Key Readings in Social Psychology. Attitudes: Their Structure, Function, and Consequences. Editors R. H. Fazio and R. E. Petty (Psychology Press), 7-15.

Conflict of Interest: The authors declare that the research was conducted in the absence of any commercial or financial relationships that could be construed as a potential conflict of interest.

Publisher's Note: All claims expressed in this article are solely those of the authors and do not necessarily represent those of their affiliated organizations, or those of the publisher, the editors, and the reviewers. Any product that may be evaluated in this article, or claim that may be made by its manufacturer, is not guaranteed or endorsed by the publisher.

Copyright (c) 2022 Sripaoraya, Spronken-Smith and Longnecker. This is an openaccess article distributed under the terms of the Creative Commons Attribution License (CC BY). The use, distribution or reproduction in other forums is permitted, provided the original author(s) and the copyright owner(s) are credited and that the original publication in this journal is cited, in accordance with accepted academic practice. No use, distribution or reproduction is permitted which does not comply with these terms. 